\title{
Social networks and wages in Senegal's labor market
}

\author{
Nicoletta Berardi
}

\section{Correspondence:}

Nicoletta.Berardi@banque-france.fr Banque de France and Toulouse School of Economics, Banque de France, 31, rue Croix des Petits Champs, 75001 Paris, France

\begin{abstract}
We develop a theoretical framework that considers the role played by moral hazard and the diversity of networks and cultures in the choice of hiring channel. In favoritism contexts social networks, and particularly strong ties, are adopted as hiring channels for unskilled jobs and result in wage penalties, while otherwise the opposite happens. We estimate an endogenous switching model for the case of Senegal's manufacturing formal sector and find, consistently with our theoretical predictions in case of favoritism, that informal hiring channels are preferred to fill unskilled vacancies and are associated with a wage penalty, especially when ties are stronger.
\end{abstract}

JEL Classification: $012 ;$ J31

Keywords: Social networks, Hiring channel, Wage differential

\section{Introduction}

Why are some workers hired through social networks, while other employees through formal channels, and what is the effect of the hiring channel on their wages? In this paper we theoretically explore the circumstances in which either informal ${ }^{1}$ or formal hiring channels are preferred and either positive or negative wage differentials emerge, considering the role played by moral hazard and the diversity of networks and cultures in the choice of hiring channel. On the empirical side, we investigate the adoption of social networks as hiring channels and its impact on wages in the case of a developing country, Senegal, whereas the others contributions to this topic generally focus on OECD countries.

An impressive number of vacancies are filled through informal hiring channels, which comprise family, friends, and in general social networks to which individuals belong, rather than through the formal labor market. Granovetter (1973), Rees (1966) and Corcoran (1980) find that about half of the jobs in the United States are filled through personal contacts and Ioannides and Loury (2004) notice that the role played by networks increased over time. Sociologists and economists have first looked at the supply side of the labor market. Holzer (1988), for example, show that when multiple search methods are possible, workers prefer social networks to formal hiring channels, because the former are less expensive and characterized by a higher probability of being hired than the latter. On the demand side, the traditional wisdom among economists ${ }^{2}$ is that informal hiring channels may help to mitigate selection problems arising in recruitment. For instance,

(c) 2013 Berardi; licensee Springer. This is an Open Access article distributed under the terms of the Creative Commons Attribution License (http://creativecommons.org/licenses/by/2.0), which permits unrestricted use, distribution, and reproduction in any medium, provided the original work is properly cited. 
Montgomery (1991), Saloner (1985) and Simon and Warner (1992) all argue that informal hiring channels may reduce information asymmetry between employers and employees and provide a better matching of unobservable characteristics. Montgomery assumes that social networks are based on homophily of unobservable characteristics, so that people tend to refer others like themselves. Saloner's results rest instead on the referees' willingness to safeguard their reputation. Simon and Warner posit that the use of informal hiring channels reduces employers' uncertainty about applicants productivity.

All these models predict that hiring through social networks should always be preferred to formal channels. Moreover, the enhanced selection that is guaranteed by informal hiring channels should be specially exploited for vacancies requiring high skills and should imply wage premia for workers hired through social networks.

However, in the real world, formal and informal hiring channels coexist and their adoption greatly varies in different contexts. First of all, the practice of hiring through social networks is even more pronounced in developing countries than in industrialized ones. ${ }^{3}$ Moreover, many empirical studies suggest that vacancies for unskilled occupations are more likely to be filled through social networks than jobs requiring high skills, ${ }^{4}$ while some find the opposite ${ }^{5}$. Finally, wage differentials imputable to informal hiring channels are far from being found always positive. ${ }^{6}$ For instance, Pellizzari (2009) finds that, out of 15 industrialized countries, in Austria, Belgium and the Netherlands networked workers enjoy wage premia, in Greece, Italy, Portugal and UK they suffer wage penalties, while in the 8 remaining countries there are no significant wage differentials imputable to the adopted hiring channel.

The discrepancies between theoretical predictions and empirical studies suggest that theories focusing on adverse selection overlook some crucial aspect of the phenomenon. This paper aims at reconciling theory and empirical findings on the choice of hiring channel and its potential effect on wages. It does so, first of all by taking into account that, besides selection issues, incomplete information may also imply problems of moral hazard. Second, it considers that networks differ in their tightness ${ }^{7}$, while the existing theoretical literature does not consider the variety of social networks. ${ }^{8}$ We argue that the strength of links is important, because tight networks are able to exert peer pressure to ensure proper behavior of members who are hired through them. ${ }^{9}$ Shapiro and Stiglitz (1984) show that, when observing employees' effort is costly for firms, employers need to increase workers' expected value of not shirking with respect to shirking. That is, firms need to rise either the monitoring or the salary of their workers. ${ }^{10}$ However, the role played by peer pressure may decrease the monitoring costs for workers hired through social networks with respect to other employees. ${ }^{11}$ Third, even networks characterized by similar tightness may play a very different role in the job market depending on the culture. There are contexts in which a worker hired through a social network reciprocates the working opportunity by exerting more effort than workers hired through the formal channel, while a culture of favoritism encourages networked employees to work less than the others. ${ }^{12}$ Our model integrates all these aspects and explains why either formal or informal hiring channels are adopted and why either positive or negative wage differentials may emerge for workers hired through informal channels, depending on circumstances. Moreover, it accounts for the stylized facts that developing countries rely even more on social networks as hiring channels than industrialized ones and that informal hiring channels are often adopted to fill unskilled vacancies. 
The paper also contributes to the empirical literature by investigating the determinants of hiring channels at worker, network and firm level and the impact of the adopted hiring channel on wages in the Senegalese formal manufacturing sector. While most of the empirical literature on social networks as hiring channels is largely confined to developed countries studies, very few studies have analyzed the crucial role of social networks in less developed countries' labor markets (notable exceptions are Egypt's studies by Assaad (1997) and Wahba and Zenou (2005)) and none takes into account the fact that social networks differ in their tightness. Moreover, to our knowledge the only existing analysis of informal hiring channels concerning Sub-Saharan Africa refers to the colonial period (Fafchamps-and-Moradi (2009)). However, this region is pervaded with informality to a greater extent than other developing countries ${ }^{13}$ and social networks play a crucial role in their labor markets ${ }^{14}$. At the same time, Senegal is a rare example of a Sub-Saharan African country characterized by a dynamic economy moving away from the ubiquitous informality to a market economy, thus providing a unique opportunity to investigate the remains of informality in an economy that is developing toward formal markets.

Estimating an endogenous switching model, ${ }^{15}$ we find that informal hiring channels are preferred to fill unskilled vacancies and are associated with a wage penalty. Moreover, the probability of having been hired through a social network and the absolute value of wage penalties is increasing with the strength of ties. These findings are consistent with our theoretical predictions in contexts where favoritism is widespread.

Section 2 analyzes the case of Senegal, providing details on the data and some descriptive statistics characterizing sampled firms and workers. Section 3 presents a theoretical framework that accounts for the elements intuitively singled out above and corroborated by the analysis of rough data. Section 4 presents econometric evidence supporting the hypotheses and the predictions of our theoretical framework. Finally, Section 5 concludes.

\section{Descriptive statistics}

The empirical analysis relies on the Investment Climate Assessment (ICA) survey for Senegal, run by the World Bank in 2003. It provides information about 262 firms and 1637 of their workers in the formal ${ }^{16}$ manufacturing ${ }^{17}$ sector. One of the salient features of this data set is that it matches workers and firms, which allows controlling for idiosyncratic characteristics of both.

Social networks based on family or friends are the main channel of matching between firms and workers in the data set. On the demand side, the majority of firms use sometimes formal and sometimes informal hiring channels, and $60 \%$ of sampled firms declare to mainly rely on informal networks in order to fill their vacancies. On the supply side, $65 \%$ of interviewed workers found their job through social networks. ${ }^{18}$

In order to get some insights about the phenomenon, it is useful to analyze the characteristics of both firms and workers thoroughly. Some characteristics of the sampled firms are reported in Table 1, which distinguishes between firms that declare to mainly rely on formal and on informal hiring. All sampled firms are located in an urban area and $95 \%$ of them in the capital city, reflecting the distribution of manufacturing employees in the country. ${ }^{19}$

Enterprises where the owner is also the director of the firm are also those that more often use informal hiring channels, while bigger firms tend to rely more on formal hiring channels. 
Table 1 Characteristics of sampled firms by their main hiring channels

\begin{tabular}{|c|c|c|c|c|}
\hline & \multicolumn{3}{|c|}{ Firms mainly hiring through channel: } & \multirow[b]{2}{*}{ Total } \\
\hline & formal & informal & Difference & \\
\hline total number of interviewed firms & 104 & 152 & -48 & 256 \\
\hline firm located in Dakar & 98 & 145 & -47 & 243 \\
\hline public firm & 8 & 4 & $4^{*}$ & 12 \\
\hline \multirow[t]{2}{*}{ mean number of employees } & 194 & 72 & $122^{* *}$ & 130 \\
\hline & (592) & $(180)$ & $(51)$ & $(425)$ \\
\hline owner and director & 59 & 105 & $-46^{* *}$ & 164 \\
\hline sector: agro-industry & 40 & 53 & -13 & 93 \\
\hline chemical/paint products & 13 & 17 & -4 & 30 \\
\hline building materials & 10 & 8 & 2 & 18 \\
\hline furniture & 1 & 5 & -4 & 6 \\
\hline metals & 10 & 15 & -5 & 25 \\
\hline paper industry & 12 & 24 & -12 & 36 \\
\hline plastics & 3 & 12 & $-9^{*}$ & 15 \\
\hline textile and leather & 8 & 15 & -7 & 23 \\
\hline wood & 7 & 3 & $4^{*}$ & 10 \\
\hline
\end{tabular}

Having noticed these characteristics at the firm level, we now turn to explore the characteristics of sampled workers. ${ }^{20}$ Table 2 reports available information about sampled employees, distinguishing between those hired through formal channels and those who found their job through social networks. Workers who found their job through networks of relatives or friends are about $65 \%$ of interviewed workers. The survey also provides information concerning two types of social networks. The first one is the network binding the owner or manager of the firm with employees belonging to her ethnic group. ${ }^{21}$ The second one includes members of her extended family working in the firm. ${ }^{22}$ Rough data suggest that the ethnic group is one of the social networks whereby workers may be hired, since employees that belong to the same ethnic group as the head of the firm are $21 \%$ among workers hired through an informal network and 13\% in the formal labor market. Since family ties are likely to be tighter than merely ethnic ones, the comparison between their effects enables to test the role played by network tightness in the labor market. ${ }^{23}$

Our data set provides evidence that workers are hired more often through social contacts for jobs requiring lower qualifications. Indeed, $76 \%$ of unskilled workers found their job through their family or friends. The percentage falls to $60 \%$ for skilled blue collars and to $41 \%$ for skilled white collars and managers. ${ }^{24}$ Workers who found their job through informal contacts are also less educated, less experienced, and younger than employees hired on the formal labor market. Finally, the mean of the natural logarithm of real monthly salary at the time of hiring ${ }^{25}$ is significantly lower for workers hired through social networks.

While the rigor of econometrics is necessary to disentangle the relative role played by different variables, the analysis of crude data suggests several potentially relevant dimensions, which are integrated in the theoretical framework developed in Section 3.

\section{A model of hiring through formal and informal channels}

The need of a theoretical framework accounting for what we observe in reality and in the data described in Section 2 motivates our modeling exercise. In order to understand 
Table 2 Characteristics of sampled workers by their hiring channel

\begin{tabular}{|c|c|c|c|c|}
\hline & \multicolumn{3}{|c|}{ Workers hired through channel: } & \multirow[b]{2}{*}{ Total } \\
\hline & formal & informal & Difference & \\
\hline number of workers & 555 & 1018 & -463 & 1573 \\
\hline same ethnicity as firm's head & 71 & 214 & $-143^{* * *}$ & 285 \\
\hline same family as firm's head & 30 & 150 & $-120^{* * *}$ & 180 \\
\hline job: managers & 32 & 23 & $9^{* * *}$ & 55 \\
\hline skilled white collar & 101 & 71 & $30^{* * *}$ & 172 \\
\hline skilled blue collar & 238 & 351 & $-113^{* * *}$ & 589 \\
\hline unskilled workers & 183 & 569 & $-386^{* * *}$ & 752 \\
\hline \multirow[t]{2}{*}{ mean education (years) } & 13.0 & 10.5 & $2.5^{* * *}$ & 11.4 \\
\hline & $(4.73)$ & $(4.62)$ & $(0.26)$ & $(4.81)$ \\
\hline \multirow[t]{2}{*}{ mean previous experience (years) } & 5.0 & 4.1 & $0.9^{* * *}$ & 4.5 \\
\hline & $(6.39)$ & $(6.06)$ & $(0.34)$ & (6.19) \\
\hline \multirow[t]{2}{*}{ mean age at hiring (years) } & 29.9 & 28.8 & $1.1^{* * *}$ & 29.2 \\
\hline & $(7.41)$ & (8.34) & $(0.42)$ & $(8.04)$ \\
\hline gender: male & 447 & 840 & -393 & 1287 \\
\hline marital status: married & 377 & 647 & $-270^{* *}$ & 1024 \\
\hline origin: Dakar & 220 & 426 & -206 & 646 \\
\hline other in Senegal & 311 & 546 & -235 & 857 \\
\hline other & 24 & 45 & -21 & 69 \\
\hline \multirow[t]{2}{*}{ weekly work hours } & 43.2 & 43.3 & -0.1 & 43.2 \\
\hline & $(8.51)$ & (9.98) & $(0.50)$ & (9.48) \\
\hline \multirow[t]{2}{*}{ mean In real monthly salary } & 11.2 & 10.9 & $0.3^{* * *}$ & 11.0 \\
\hline & $(0.87)$ & $(0.86)$ & $(0.05)$ & $(0.88)$ \\
\hline
\end{tabular}

Note: Standard deviation in brackets. Significance levels based on Whicoxon-Mann-Whitney (for continuous variables) and Fisher exact (for categorical variables) test: *: 10\%**: 5\%***: $1 \%$.

the use of social networks as hiring channels, the key point is investigating why and when firms and applicants prefer to rely on them. Since adverse selection has long been investigated in the context of the hiring channel choice without managing to account for empirical evidence, we abstract from it for the sake of tractability and we focus instead on other crucial characteristics of the phenomenon that received little attention until now, like the role played by moral hazard and network characteristics. Moreover, we simultaneously take into account the choices of employers and applicants.

\subsection{Basic model}

We model a formal sector firm that can hire labor either through the formal channel or from a pool of workers who are linked to that firm by a social network. ${ }^{26}$ The wage is determined by the bargaining between firm $j$ and worker $i .^{27}$ Assume that the outcome is determined by the Generalized Nash Bargaining Solution (Rubinstein 1982), so that the wage paid to a worker maximizes $\left(w^{k}-\underline{w}^{k}\right)^{\eta}\left(\bar{w}^{k}-w^{k}\right)^{1-\eta}$, where $k \in\{F, N\}$ is the hiring channel.

In this function, $\eta$ is the worker's bargaining power, $\underline{w}^{k}$ is the lower bound of wages that the employee is willing to accept and $\bar{w}^{k}$ is the wage upper bound that the firm is prepared to pay the worker hired through channel $k$. The corresponding wage will be determined as $w^{k}=\eta \bar{w}^{k}+(1-\eta) \underline{w}^{k}$. This expression simply says that the agreed wage will be a linear combination of the two extreme points of the bargaining set, being closer to the top the higher is the worker's bargaining power. The lower and upper bounds $\underline{w}^{k}$ and $\bar{w}^{k}$ are determined endogenously, as described below. 
We assume that the firm can observe the worker's individual output only by costly monitoring her. For the sake of simplicity, for the moment we hypothesize that the worker can either shirk or exert some effort, i.e., $e^{k} \in\{0, e\}$, at per unit cost $\gamma$. Section 3.2 develops an extension of the model where the effort exerted may be different between hiring channels $\left(e^{N} \neq e^{F}\right)$. Assume that the monitoring technology is such that the worker will be fired if she is caught shirking, which happens with probability $\mu^{k}$ when she does. Moreover, there exists an exogenous probability of separation $q$, as in Shapiro and Stiglitz (1984) ${ }^{28}$.

Denote $U^{k}$ the life-time expected utility of an unemployed worker and $E^{k}$ the life-time expected utility of a worker employed through hiring channel $k$. The Bellman equation for a worker hired through the formal channel and not shirking at steady state is:

$$
r E_{\text {no-shirking }}^{F}=w^{F}-\gamma e-q\left(E_{\text {no-shirking }}^{F}-U^{F}\right)
$$

while that of a shirking worker hired through the same channel would be:

$$
r E_{\text {shirking }}^{F}=w^{F}-\left(q+\mu^{F}\right)\left(E_{\text {shirking }}^{F}-U^{F}\right)
$$

Similarly, the Bellman equation for a worker hired through a social network and not shirking at steady state is:

$$
r E_{n o-\text { shirking }}^{N}=w^{N}+\zeta-\gamma e-q\left(E_{\text {no-shirking }}^{N}-U^{N}\right) .
$$

Expression (3) resembles (1), except for the parameter $\zeta \geq 0$. The latter represents the non-monetary gains that a worker may derive from working with or for a member of her social networks. This parameter captures the benefits that the worker can get from being an active member of the network, including gifts in special occasions like weddings and various kinds of help. ${ }^{29}$ The Bellman equation for a worker hired through social networks and shirking at steady state would be:

$$
r E_{\text {shirking }}^{N}=w^{N}+\zeta-\mu^{N} \varphi-\left(q+\mu^{N}\right)\left(E_{\text {shirking }}^{N}-U^{N}\right) .
$$

In expression (4) two additional parameters play a role with respect to expression (2): the aforementioned potential non-monetary gains $(\zeta)$ and network tightness $(\varphi)$, which is the strength that characterizes its links. The idea is that a worker hired through a social network may feel peer pressure by members of her hiring channel not to compromise its reputation and, if she is caught shirking, she will be punished by the network that served as hiring channel to an extent that depends on network tightness. Finally, the Bellman equation for an unemployed worker at steady state is $r U^{k}=a\left(E^{k}-U^{k}\right)$, where unemployment benefits are assumed to be null and the job-acquisition rate $a$ exogenous.

Lemma 1 (No-Shirking Conditions). When formal and informal channels are adopted the no-shirking conditions are respectively:

$$
\begin{aligned}
\mu^{F} & \geq \frac{\gamma e(r+a+q)}{w^{F}-\gamma e} \\
\mu^{N} & \geq \frac{\gamma e(r+a+q)}{w^{N}+\zeta-\gamma e+\varphi(r+a+q)}
\end{aligned}
$$

The proof is provided in Appendix A. The no-shirking conditions (5) and (6) suggest that the intensity of monitoring that maximizes firm's profit depends on the chosen hiring channel. This result is a direct consequence of the fact that the utility of workers depends on their hiring channel. Indeed, when a social network is adopted as hiring channel, its 
tightness affects the level of monitoring inducing effort. Moreover, the larger the nonmonetary benefit enjoyed by networked workers, the lower the monitoring needed to induce their effort.

In our framework firms always induce effort, since shirking workers are not productive. The no-shirking conditions (5) and (6) hold as equalities, since this is the value of $\mu^{k}$ that maximizes the firm's profit per worker when monitoring is costly. More formally, denote $\vartheta$ labor productivity and $\xi$ the unit cost of monitoring. The Bellman equation for employing a worker hired through channel $k$ at steady state, assuming that the expected discounted payoff of having a vacancy is zero, is $r \Pi^{k}=\vartheta e^{k}-w^{k}-\xi \mu^{k}-q \Pi^{k}$, such that in the case of an employee hired on the formal labor market $(k=F) e^{F}=e$ if $\mu^{F} \geq \frac{\gamma e(r+a+q)}{w^{F}-\gamma e}$, and $e^{F}=0$ if $\mu^{F}<\frac{\gamma e(r+a+q)}{w^{F}-\gamma e}$, while for a worker hired through a social network $(k=N)$ $e^{N}=e$ if $\mu^{N} \geq \frac{\gamma e(r+a+q)}{w^{N}+\zeta-\gamma e+\varphi(r+a+q)}$, and $e^{N}=0$ if $\mu^{N}<\frac{\gamma e(r+a+q)}{w^{N}+\zeta-\gamma e+\varphi(r+a+q)}$.

Therefore, per worker profit when the firm hires through respectively formal and informal channel may be written at equilibrium as:

$$
\begin{aligned}
\Pi^{F} & =\frac{\vartheta e-w^{F}}{r+q}-\xi \frac{\gamma e(r+a+q)}{\left(w^{F}-\gamma e\right)(r+q)} \\
\Pi^{N} & =\frac{\vartheta e-w^{N}}{r+q}-\xi \frac{\gamma e(r+a+q)}{\left[w^{N}+\zeta-\gamma e+\varphi(r+a+q)\right](r+q)}
\end{aligned}
$$

which are assumed to be non-negative.

Proposition 1 (Bargaining Set). The upper and lower bound of the bargaining set are determined as follows:

1. workers prefer a job through the informal channel if:

$$
w^{N} \geq w^{F}-\zeta
$$

2. firms prefer hiring through social networks if:

$$
w^{N}+\xi \frac{\gamma e(r+a+q)}{w^{N}+\zeta-\gamma e+\varphi(r+a+q)} \leq w^{F}+\xi \frac{\gamma e(r+a+q)}{w^{F}-\gamma e}
$$

Proposition 1, whose proof is provided in Appendix A, formalizes the idea that for informal hiring to take place, such a transaction must be worthwhile for both the firm and the worker. In other words, as a familiar saying suggests, 'it takes two to tango'.

Proposition 2 (Choice of Hiring Channel). The hiring channel is determined as follows:

1. informal hiring channels will be always used if:

- $\zeta>0$, or

- $\zeta=0$ and $\varphi>0$;

2. informal and formal hiring channels are indifferent if $\zeta=0$ and $\varphi=0$.

Intuitively, informal hiring channels prevail in the presence of non-monetary gains. Even in their absence, hiring through social networks is preferred when their links are strong. 
Depending on the values of $\zeta$ and $\varphi$ workers hired through the informal channel get a wage premium or a wage penalty with respect to employees hired through the formal labor market.

Proposition 3 (Wage Differential). The wage differential between hiring channels is determined as follows:

1. no wage penalty to workers hired through social networks is possible if $\zeta=0$;

2. both wage premium and penalty are possible, depending on the bargaining power, if $\zeta>0$.

Proposition 3 implies that when workers hired through social networks enjoy some non-pecuniary gains they may either earn a wage premium or suffer a wage penalty, consistently with the heterogeneous empirical findings discussed in Section 1. More specifically, if non-monetary benefits exist, the larger they are, the lower the minimum wage that workers hired through social networks are willing to accept $\left(\underline{w}^{N}\right)$ and, at the same time, the higher the maximum wage that firms are willing to pay to workers hired through social networks $\left(\bar{w}^{N}\right)$. The latter is also increasing with the tightness characterizing the network that served as hiring channel. Indeed, strong links allow firms to monitor less workers that are subject to peer pressure within their social network.

\subsection{The role of culture}

We now extent the basic setting presented in Section 3.1 by introducing the potential role of culture. The idea is that worker's effort and thus productivity may be influenced by how she was hired. We now assume that a worker hired through the formal channel chooses $e^{F} \in\{0, e\}$, while somebody hired through social networks $e^{N} \in\{0, e+\delta \varphi\}$. Indeed, the characteristics of the social network whereby a worker is hired, and namely its tightness $(\varphi)$, may influence the extent of her effort.

In some contexts workers hired through social networks may be eager to reciprocate the working opportunity, while elsewhere they may feel that they don't need to exert as much effort as the others (i.e., the sign of $\delta$ is culturally driven).

In this context, the Bellman equation for a worker hired through social networks and not shirking at steady state is:

$$
r E_{n o-s h i r k i n g}^{N}=w^{N}+\zeta-\gamma(e+\delta \varphi)-q\left(E_{\text {no-shirking }}^{N}-U^{N}\right)
$$

while that of a worker hired through the same channel and shirking is unchanged (see expression (4) in Section 3.1). The Bellman equations for a worker hired through the formal channel respectively not shirking and shirking are not affected either and correspond to expressions (1) and (2) in Section 3.1.

Lemma 2 (No-Shirking Conditions - extended to account for culture). When formal and informal channels are adopted the no-shirking conditions are respectively:

$$
\begin{aligned}
\mu^{F} & \geq \frac{\gamma e(r+a+q)}{w^{F}-\gamma e} \\
\mu^{N} & \geq \frac{\gamma(e+\delta \varphi)(r+a+q)}{w^{N}+\zeta-\gamma(e+\delta \varphi)+\varphi(r+a+q)}
\end{aligned}
$$


If culture is allowed to play a role, the Bellman equation for employing a non-shirking worker hired through a social network at steady state is modified as follows with respect to the Section 3.1:

$$
r \Pi^{N}=\vartheta(e+\delta \varphi)-w^{N}-\xi \frac{\gamma(e+\delta \varphi)(r+a+q)}{w^{N}+\zeta-\gamma(e+\delta \varphi)+\varphi(r+a+q)}-q \Pi^{N}
$$

Therefore, intuitively, with respect to the basic case, when culture is such that productivity of workers hired through social networks is higher than that of workers hired through the formal channel, the lower bound of wages that workers accept $\left(\underline{w}^{N}\right)$ and the upper bound of wages that firms are willing to pay $\left(\bar{w}^{N}\right)$ increase, and the more so the tighter the network that served as hiring channel. More formally, proposition 4 specifies the acceptable range of values of the informal wage for making a transaction through this channel.

Proposition 4 (Bargaining Set - extended to account for culture). The upper and lower bound of the bargaining set are determined as follows:

1. workers prefer a job through the informal channel if:

$$
w^{N} \geq w^{F}-\zeta+\gamma \delta \varphi
$$

2. firms prefer hiring through social networks if:

$$
w^{N}-\vartheta \delta \varphi+\xi \frac{\gamma(e+\delta \varphi)(r+a+q)}{w^{N}+\zeta-\gamma(e+\delta \varphi)+\varphi(r+a+q)} \leq w^{F}+\xi \frac{\gamma e(r+a+q)}{w^{F}-\gamma e}
$$

If the monitoring cost is relatively low and the cultural context is such that workers hired through social networks are willing to exert extra effort to reciprocate $(\delta>0)$, the upper bound is increasing with network tightness, reciprocity, and productivity. If instead networked workers exert less effort than employees hired through the formal channel $(\delta<0)$, the upper bound is decreasing with network tightness, the extent of favoritism (i.e., the absolute value of $\delta$ ), and productivity.

At the other end of the range, the lower bound is smaller the larger the non-monetary benefits that the worker gets. When workers hired through social networks are eager to reciprocate the working opportunity, the lower bound increases with network tightness, while it decreases when networked workers exert less effort.

Figure 1 depicts the set determined by proposition 4 . For wages beyond $\widehat{w}^{F}$, defined as the point where $\bar{w}^{N}$ and $\underline{w}^{N}$ coincide, workers do not want a job through social networks because firms are not willing to pay them enough through such hiring channel. Only within the area labeled 'informal hiring channel' both sides are willing to use informal channels.

Proposition 5 (Choice of Hiring Channel - extended to account for culture). When $\delta>0$ (i.e., in a culture of gratitude),

1. informal hiring channels will be used:

- always if $\vartheta \geq \gamma-\zeta / \delta \varphi$, or

- only when $w^{F}$ is below the threshold level $\widehat{w}^{F}$ if $\vartheta+\zeta / \delta \varphi<\gamma$; 


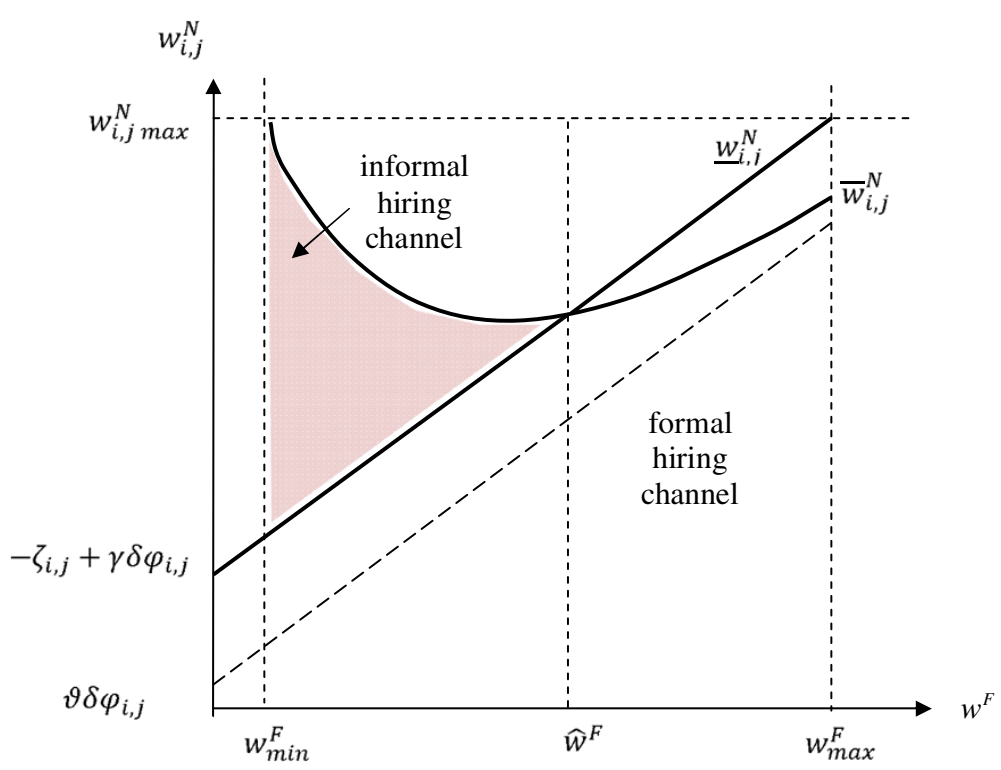

Figure 1 The choice of hiring channel and the wages of workers hired through formal and informal hiring channels.

2. informal and formal hiring channels are indifferent if $\vartheta+\zeta / \delta \varphi<\gamma$ and $w^{F}=\widehat{w}^{F}$;

3. formal hiring channels will be used otherwise.

When $\delta<0$ (i.e., in a culture of favoritism),

1. informal hiring channels will be used:

- always if $\gamma \geq \vartheta+\zeta / \delta \varphi$, or

- only when $w^{F}$ is below the threshold level $\widehat{w}^{F}$ if $\gamma-\zeta / \delta \varphi<\vartheta$;

2. informal and formal hiring channels are indifferent if $\gamma-\zeta / \delta \varphi<\vartheta$ and $w^{F}=\widehat{w}^{F}$;

3. formal hiring channels will be used otherwise.

Indeed, only informal hiring channel are used when the area labeled informal hiring channel' becomes open-ended, that is when either $\zeta>\varphi \delta(\gamma-\vartheta)$ or, if $\zeta \rightarrow 0$, when $\delta(\gamma-\vartheta) \leq 0$. Intuitively, the first condition suggests that social networks prevail as hiring channel when non-monetary gains from informal hiring are substantial. Since in developing countries social networks are often very important and informal exchanges widespread, the relative weight of non-monetary benefits versus salary may be substantial. Therefore, our theoretical framework predicts that informal hiring channels should be even more common in developing countries than in industrialized countries. At the same time, since the same non-monetary gains impact on workers' utility more if their salary is lower, social networks should be more often adopted as hiring channel for less skilled jobs.

Even when networks do not provide high non-monetary benefits, only informal hiring channels are adopted if $\vartheta \geq \gamma$ when $\delta>0$ and if $\gamma \geq \vartheta$ when $\delta<0$. If the spread between productivity and cost of effort of a worker is increasing with her skills, our framework predicts that informal hiring channels should be preferred to fill skilled vacancies, when the culture is such that a worker hired through a social network reciprocates the working opportunity by exerting more effort than workers hired through the formal channel 
$(\delta>0)$. At the same time, in contexts of favoritism $(\delta<0)$ they should be preferred for unskilled jobs, while skilled vacancies should be filled through formal channels.

Figure 1 shows that the stronger the willingness to reciprocate a job opportunity obtained through social networks and the tightness of the social network adopted as hiring channel, the higher can be the wage of a worker hired through informal channels. The opposite is true the stronger the culture of favoritism and the tighter the social network adopted as hiring channel. When the bargaining power is limited, the salary earned by workers hired through the informal channel decreases with the non-monetary gains workers enjoy, while, if networked employees have strong bargaining power, the effect is weaker and the more so the larger the non-monetary gains.

We now formally assess when workers hired through the informal channel get a wage premium or a wage penalty with respect to employees hired through the formal channel.

Proposition 6 (Wage Differential - extended to account for culture). When $\delta>0$,

1. both wage premium and penalty are possible, depending on the bargaining power, if $\zeta>\gamma \delta \varphi$;

2. only wage premium to workers hired through social networks is possible if $\zeta<\gamma \delta \varphi$.

When $\delta<0$,

1. both wage premium and penalty are possible, depending on the bargaining power.

Proposition 6 suggests, that depending on the parameter values, informal hiring channels may have either positive or negative consequences on salaries, as hinted by the empirical literature. In particular, wage penalties should be more likely in contexts of favoritism and wage premia in the opposite case. ${ }^{30}$ Even in case of low bargaining power, workers hired through social networks earn for sure wage premia when they reciprocate the working opportunity by exerting more effort than workers hired through formal channels if non-monetary gain don't exist. In such a culture, the value of wage premia are ceteris paribus positively affected by network tightness and the intensity of reciprocity. On the other hand, in contexts of favoritism, workers hired through informal hiring channels can get wage premia only if the bargaining power is particularly strong.

\section{Hiring channel choice and wage differentials in Senegal}

The model developed in Section 3 provides a theoretical framework to understand the different mechanisms that may play a role in the choice of hiring channel and the way it affects wages. In particular, it explains why wither informal or formal hiring channels are preferred and wither positive or negative wage differentials emerge for workers hired through social networks, depending on circumstances. The model predicts that, conditional on being employed, in favoritism contexts social networks are likely to be adopted as hiring channels for unskilled jobs and to result in wage penalties and even more, the stronger the ties, while otherwise the opposite happens.

We now turn to empirically analyze in a concrete case whether the choice of hiring channel and wage differentials are consistent with the theoretical predictions either in a favoritism or in a reciprocity context. We exploit the Senegalese data to investigate the determinants of hiring channel choice and wage differentials imputable to the hiring channel. ${ }^{31}$ 
A fundamental concern undermines the analysis: is the hiring channel choice exogenous to unobservable determinants of wage? If hiring channel and salary share some unobservable determinants, sample selection ${ }^{32}$ biases the estimation of coefficients. If for instance less able individuals are more likely to be hired through social networks than through formal channels and therefore receive lower wages ceteris paribus, then failing to control for this correlation would yield biased estimates of the impact of hiring channel on wages.

Besides the potential sample selection bias, a further concern is that the hiring channel may have an indirect impact on the salary through the standard wage determinants. For example, the role played by a worker's education on her wage may be weaker for an applicant hired through social networks than for one hired on the formal labor market. The econometric framework addressing at the same time the endogenous sample selection and the switching impact that wage determinants may have for workers hired through different channels is the endogenous switching model (see Heckman 1979). Roughly speaking, it is a treatment effect model that allows for a full set of interaction terms between the hiring channel and the standard determinants of wage. Some details on the endogenous switching econometric model are given in Appendix B.

\subsection{Specification of estimation}

To take advantage of the richness of the available data, we take into account not only variables at the individual level as in the standard endogenous switching model, but also firms' characteristics. ${ }^{33}$ Therefore, the system of equations of interest is as follows:

$$
\begin{aligned}
\ln w_{i, j}^{F} & =\beta_{\text {worker }}^{F} X_{i}+\beta_{\text {firm }}^{F} \Xi_{j}+\epsilon_{i, j}^{F} \\
\ln w_{i, j}^{N} & =\beta_{w o r k e r}^{N} X_{i}+\beta_{f i r m}^{N} \Xi_{j}+\epsilon_{i, j}^{N} \\
H_{i, j}^{*} & =\gamma Z_{i, j}+u_{i, j}
\end{aligned}
$$

where the dependent variable of the wage regressions is the natural logarithm of the real monthly wage at the time of hiring, $X_{i}$ are the regressors at worker $i$ level, $\Xi_{j}$ the characteristics of firm $j$, and $Z_{i, j}$ includes $X_{i}, \Xi_{j}$ and potentially instrumental variables that allow the parametric identification. In particular, the vector $X_{i}$ is represented by worker i's years of education and experience before the current job, gender, marital status, place of origin, number of hours worked per week, ${ }^{34}$ type of vacancy filled when hired, whether worker $i$ is a relative of firm's manager or owner, or does not, but belongs to her ethnic group. The vector $\Xi_{j}$ includes firm $j$ 's size, sector, and three dummy variables taking unit value respectively if firm $j$ is located in Dakar, if a large share of its capital belongs to the State, and if its owner personally runs the firm (see Table 6 in Appendix B for a summary of variables).

While the available data allow controlling for a great variety of observable characteristics both at worker and firm level, it may still be the case that some unobserved characteristics differ between individuals hired through different hiring channels. The best available exclusion restriction is a dummy taking unit value when a worker was over 40 years old when hired. ${ }^{35}$ The identifying assumption is that this variable is legitimately excluded from wage regressions (15) and (16), but significant in the selection equation (17). While by definition this hypothesis is not testable, economic reasoning supports our choice of this exclusion restriction. Indeed, it is standard to posit that age should not be relevant in wage determination once experience and education are accounted for. ${ }^{36}$ 
The hypothesis that relatively old workers ${ }^{37}$ looking for a job are more likely to be hired through informal rather than formal channels is supported by Delattre and Sabatier (2007) and it is consistent with our theoretical framework in contexts of favoritism. Indeed, older people have larger and tighter social networks available than younger workers. Moreover, the burden of reconversion of their competences, which is required by a new working environment, tends to increase the spread between their productivity and their cost of effort with respect to younger workers, so that formal hiring channels are hardly used, while peer pressure consequent to the adoption of informal hiring channels may compensate it.

Finally, the observed dichotomous realization of the latent variable $H_{i, j}^{*}$ is whether each sampled worker was hired through social networks $\left(H_{i, j}=1\right)$ or not $\left(H_{i, j}=0\right)$ :

$$
H_{i, j}=\left\{\begin{array}{l}
1 \text { if } H_{i, j}^{*}>0 \\
0 \text { otherwise }
\end{array}\right.
$$

\subsection{Econometric results}

Table 3 shows the results for the simultaneous estimation of equations (15), (16), and (17). The second column of the table reports the coefficients of the determinants of the hiring channel, which correspond to the vector of parameters $\gamma$ in equation (17). The determinants of salary for workers hired through social networks, corresponding to $\beta^{N_{\mathrm{S}}}$ in equation (16), are reported column four. Those for employees hired through formal channels, corresponding to $\beta^{F}$ in equation (15), are presented in the sixth column.

Our main object of interest in Table 3 is the type of social network whereby a worker is hired. A relative of the owner or manager of the firm ceteris paribus has significantly greater chances of being hired through informal hiring channels. At the same time, relatives suffer a substantial wage penalty. ${ }^{38}$ The role played by kinship, possibly the tightest existing network, reflects the theoretical prediction of our framework that the tighter the social network that serves as hiring channel, the larger the potential wage penalties suffered by networked workers, in contexts where favoritism is widespread. ${ }^{39}$ Indeed, the fact of belonging to the same ethnic group as the firm's head (without being a relative) has not significant impact once kinship is taken into account.

Table 3 clearly indicates that the use of social networks as hiring channel greatly varies with the type of vacancy to be filled, a stylized fact described in Section 1. Unskilled workers have a significantly higher probability of being hired through social networks than skilled blue collars (the category of reference), while the opposite is true for skilled white collars. Such result verifies the theoretical implications of the model that are developed in Section 3.2. If the spread between productivity and cost of effort of workers is decreasing with their skills, and the potential non-monetary gains quite large with respect to unskilled workers' monetary wage, networks are likely to be adopted as hiring channel despite favoritism, while the opposite is true for skilled white collar workers. Managers are not significantly more likely to be hired through formal rather than informal channels, probably because the two countervailing effects, namely large non-monetary benefits and high productivity combined with very costly monitoring, compensate each other.

Whatever the hiring channel, the coefficients of the wage regressions realistically show that a worker earns significantly more if hired as manager or a skilled white collar and less if hired as unskilled worker than if she is hired as skilled blue collar. However, the 
Table 3 Endogenous switching model: determinants of the choice of hiring channel and of the wage for workers hired through formal and informal hiring channels

\begin{tabular}{|c|c|c|c|c|c|c|}
\hline \multirow[b]{3}{*}{ same family as firm's head } & \multirow{2}{*}{\multicolumn{2}{|c|}{$\begin{array}{c}\text { Choice of } \\
\text { informal hiring } \\
\text { channel }\end{array}$}} & \multicolumn{4}{|c|}{$\begin{array}{l}\text { Wage regression for workers } \\
\text { hired through: }\end{array}$} \\
\hline & & & \multicolumn{2}{|c|}{ social networks } & \multicolumn{2}{|c|}{ formal channel } \\
\hline & $0.476^{* * *}$ & $(0.151)$ & $-0.297^{* *}$ & $(0.133)$ & $-0.216^{*}$ & $(0.115)$ \\
\hline only same ethnicity as firm's head & 0.081 & $(0.154)$ & 0.025 & $(0.089)$ & 0.178 & $(0.113)$ \\
\hline job: manager & -0.458 & $(0.287)$ & $0.629 *$ & $(0.335)$ & $0.486^{* * *}$ & $(0.107)$ \\
\hline skilled white collar & $-0.336 * *$ & $(0.145)$ & $0.436^{* * *}$ & $(0.138)$ & $0.197^{* *}$ & $(0.101)$ \\
\hline unskilled & $0.252^{* *}$ & $(0.112)$ & $-0.434^{* * *}$ & $(0.075)$ & $-0.192 * *$ & $(0.087)$ \\
\hline education (years) & $-0.030^{* *}$ & $(0.012)$ & $0.040^{* * *}$ & $(0.010)$ & $0.057^{* * *}$ & $(0.009)$ \\
\hline previous experience (years) & $-0.063^{* * *}$ & $(0.019)$ & $0.043^{* * *}$ & $(0.017)$ & $0.025^{*}$ & $(0.015)$ \\
\hline previous experience sq. (years) & $0.002^{* * *}$ & $(0.001)$ & $-0.002^{* *}$ & $(0.001)$ & -0.001 & $(0.001)$ \\
\hline age over 40 at hiring & $0.304^{* *}$ & $(0.141)$ & & & & \\
\hline origin: Dakar & -0.054 & $(0.265)$ & 0.134 & $(0.217)$ & 0.040 & $(0.259)$ \\
\hline other in Senegal & -0.215 & $(0.266)$ & 0.100 & $(0.074)$ & 0.044 & $(0.257)$ \\
\hline married & 0.108 & $(0.092)$ & 0.100 & $(0.074)$ & $0.162 * * *$ & $(0.066)$ \\
\hline gender: male & -0.042 & $(0.114)$ & -0.019 & $(0.083)$ & 0.064 & $(0.087)$ \\
\hline hours worked & 0.005 & $(0.005)$ & 0.000 & $(0.003)$ & 0.003 & $(0.004)$ \\
\hline firm located in Dakar & $-0.397^{*}$ & $(0.211)$ & $0.654^{* * *}$ & $(0.215)$ & $0.721^{* * *}$ & $(0.190)$ \\
\hline In of n.employees & $-0.110^{* * *}$ & $(0.039)$ & $0.132^{* * *}$ & $(0.032)$ & $0.058^{* *}$ & $(0.029)$ \\
\hline owner and director & 0.110 & $(0.110)$ & $-0.126^{*}$ & $(0.073)$ & -0.052 & $(0.073)$ \\
\hline TFP at hiring & 0.015 & $(0.156)$ & $0.360^{* * *}$ & $(0.120)$ & $0.477^{* * *}$ & $(0.126)$ \\
\hline public firm & 0.051 & $(0.253)$ & -0.037 & $(0.230)$ & -0.010 & $(0.131)$ \\
\hline intercept & $1.260^{* * *}$ & $(0.469)$ & $9.675^{* * *}$ & $(0.328)$ & $9.000 * * *$ & $(0.398)$ \\
\hline sector dummies & yes & & yes & & yes & \\
\hline$\rho_{N}$ & $-0.747^{* * *}$ & $(0.256)$ & & & & \\
\hline$\rho_{F}$ & -0.142 & $(0.270)$ & & & & \\
\hline Log-likelihood & -1844.84 & & & & & \\
\hline Wald $\chi_{26}^{2}$ & 128.49 & & & & & \\
\hline N & 1139 & & & & & \\
\hline
\end{tabular}

Note: Robust Standard Errors in brackets, clustered by firm

Significance levels: *: $10 \% * *: 5 \% * *: 1 \%$.

magnitude of the coefficients differs between hiring channels, a point that we will further investigate later on in this section.

Longer education is associated with a lower probability of being hired through social networks and the use of informal hiring channels is a decreasing and convex function of experience prior hiring. ${ }^{40}$ This feature is consistent with the prediction of our theoretical framework that higher productivity increases the incidence of formal channels. Education and experience, the classical Mincerian wage determinants, as expected significantly increase wages, whatever the hiring channel whereby a worker was hired.

As argued in Section 4.1, even controlling for workers' experience, people over 40 years old are significantly more likely to have found their job through informal rather than formal channels, consistently with the observation that elder people seldom get a job on the formal labor market, a phenomenon rationalized by our theoretical framework.

We control for marital status, which is not a significant determinant of the hiring channel and does not affect wages of workers hired through social networks. However, workers hired on the formal labor market enjoy significantly higher wages if they are married. ${ }^{41}$ 
Workers' gender, place of origin, and hours worked per week are maintained as control variables at the individual level, but they are never significant.

Table 3 also shows that there are a number of firms' characteristics affecting the choice of the hiring channel and wages. The location of a firm in Dakar rather than in other towns decreases the likelihood of hiring somebody through informal hiring channels. ${ }^{42}$ At the same time, employees working in a firm in Dakar gain significantly higher wages. ${ }^{43}$

The size of the firm, in terms of total number of employees, has a significantly negative impact on the probability of being hired through informal channels and a positive one on wages. ${ }^{44}$ This is consistent with our theoretical predictions, since in small firms the recruiter and the employees tend to work closely, while in large firms peer pressure is less effective.

Workers employed by a firm run by its owner are not significantly more likely to be hired through social networks, but they earn less ceteris paribus. Indeed, a manager may get positive utility out of hiring people belonging to her social networks, even in cases when the choice of informal hiring channels does not maximize the firm's expected profit, and may hire too often workers through her social networks. Instead, the utility of a director who is also the owner directly depends also on firm's profit and principal-agent distortions are avoided: she uses her social networks as hiring channel only when convenient and she pays her networked employees what is needed to induce their effort and not more than that.

To account for time effects due to the fact that surveyed workers were hired in different years, we control for the total factor productivity change, which is as expected positively strongly correlated with salaries. Finally, we control for firms' public capital and sector.

At the bottom of Table 3 are reported the estimated correlation coefficients between residuals of the regression for the choice of the hiring channel and for wages. The correlation between the residuals of the selection equation (17) and the wage regression for workers hired through formal channels (15), $\rho_{F}$, is not significantly different from zero. However, the correlation between the residuals of the selection equation and the wage regression for workers hired through informal channels (16), $\rho_{N}$, is significantly negative. Therefore, selection is endogenous and, in particular, workers hired through social networks ceteris paribus suffer a significant wage penalty due to unobservable determinants.

A visual way to see the wage penalty due to unobservable factors that is suffered by workers who got their job through social networks is to compare the true distribution of wage earned by workers hired through informal channels with the unconditional expected wage for the same subsample, i.e., $\mathbb{E}\left(\ln w_{i, j}^{N}\right)=\widehat{\beta}_{\text {worker }}^{N} X_{i}+{\widehat{\beta^{N}}}_{\text {firm }} \Xi_{j}$. Figure 2 shows that the true distribution of wages of the subsample of workers hired through informal channels is shifted toward lower wages with respect to the unconditional wage distribution predicted for the same workers. However, the distribution of expected wages for the subsample of workers hired through social networks conditional on the dependent variable being observed, i.e., $\mathbb{E}\left(\ln w_{i, j}^{N} \mid H_{i, j}=N\right)=\widehat{\beta}_{\text {worker }}^{N} X_{i}+\widehat{\beta}_{\text {firm }}^{N} \Xi_{j}+\widehat{\sigma}_{N} \widehat{\rho}_{N} f\left(\widehat{\gamma} Z_{i, j}\right) / F\left(\widehat{\gamma} Z_{i, j}\right)$, fits quite well the true distribution of wages for the same subsample. The difference between the unconditional and the conditional expected wage distribution is precisely the negative selection effect of informal hiring channels.

In order to reach a conclusion about whether all in all informal hiring channels imply on average wage penalties in the Senegalese manufacturing sector, the switching impact 


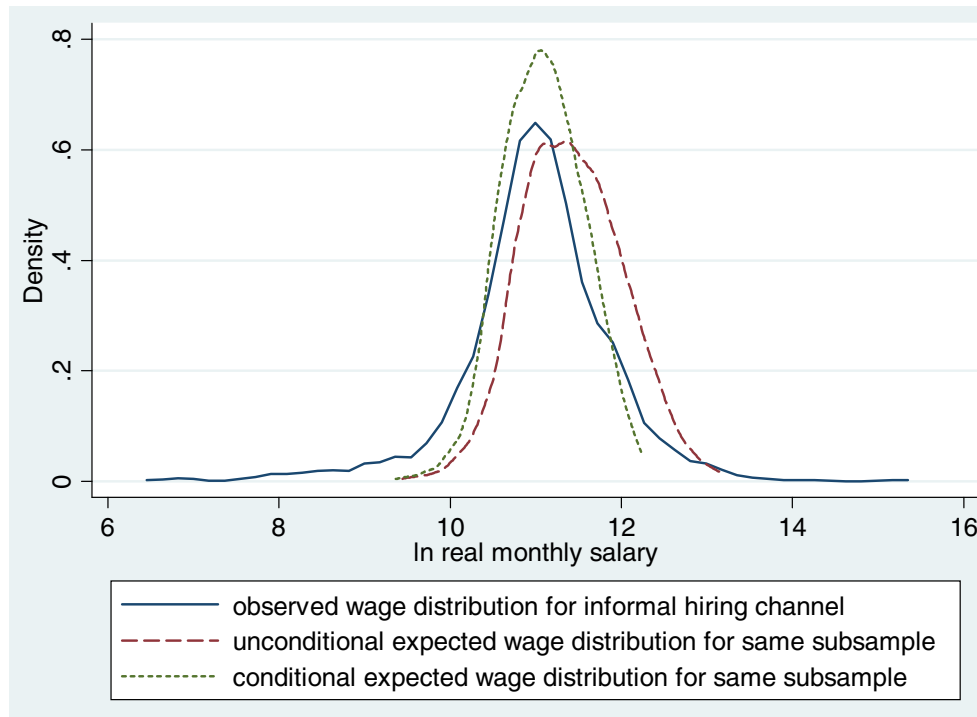

Figure 2 True distribution of wages for workers hired through informal hiring channels and distribution of unconditional and conditional expected wages for the same subsample of workers.

of observable wage determinants has to be taken into account, too. We therefore compare the estimated parameters $\widehat{\beta}^{N}$ and $\widehat{\beta}^{F}$ of Table 3 to asses whether the differences are statistically significant. Table 4 shows that informal hiring channels also entail a wage penalty due to observable determinants, but only through the switching impact of unskilled jobs.

Table 4 Switching impact of the hiring channel on wages: difference between estimated coefficients of wage determinants for workers hired through informal and formal channels $\widehat{\beta}^{N}-\widehat{\boldsymbol{\beta}}^{F}$

\begin{tabular}{lll}
\hline same family as firm's head & -0.082 & $(0.254)$ \\
only same ethnicity as firm's head & -0.153 & $(0.175)$ \\
job: manager & 0.143 & $(0.428)$ \\
$\quad$ skilled white collar & 0.239 & $(0.210)$ \\
$\quad$ unskilled & $-0.242^{* *}$ & $(0.113)$ \\
education (years) & -0.017 & $(0.056)$ \\
previous experience (years) & 0.018 & $(0.040)$ \\
previous experience sq. (years) & -0.001 & $(0.002)$ \\
origin: Dakar & 0.094 & $(0.328)$ \\
$\quad$ Senegal & 0.056 & $(0.425)$ \\
married & -0.062 & $(0.119)$ \\
gender: male & -0.083 & $(0.134)$ \\
hours worked & -0.004 & $(0.028)$ \\
firm located in Dakar & -0.067 & $(0.335)$ \\
In of n.employees & 0.074 & $(0.078)$ \\
owner and director & 0.074 & $(0.110)$ \\
TFP at hiring & -0.117 & $(0.170)$ \\
public firm & -0.027 & $(0.239)$ \\
intercept & 0.675 & $(2.538)$ \\
\hline Note: Bootstrap Standard Errors in brackets. Significance &
\end{tabular}

Note: Bootstrap Standard Errors in brackets. Significance levels: *: 10\% **: 5\% ***: 1\%. 
Jointly considering our results concerning the unobservable and observable wage determinants for workers hired through social networks and formal channels, we can conclude that the former ones suffer a significant wage penalty.

\section{Conclusions}

This paper sheds light on the role played by social networks as hiring channel and on wage differentials between employees hired through formal and informal hiring channels. It contributes to the theoretical literature on informal hiring channels and to the empirical literature on social networks as hiring channels in developing countries.

From a theoretical point of view, we focus on the role played by moral hazard and allow for heterogeneity of networks' tightness. Our framework helps to interpret the fact that firms and workers rely sometimes on formal hiring channels and sometimes on informal ones, as well as the rather mixed findings of the empirical literature on the impact that the hiring channel has on wages. In particular, the choice of the hiring channel varies with the development and the culture of a country, with the characteristics of networks available as hiring channel and with the type of vacancy to be filled. In contexts of favoritism, social networks are predicted to be mainly adopted as hiring channel to fill unskilled vacancies; moreover, such jobs may be associated with wage penalties and the more so the tighter the network that served as hiring channel. However, when skilled workers are hired through informal hiring channel, they are likely to get wage premia, and the more so the tighter the network. The opposite is predicted to happen in a culture where reciprocity prevails.

We empirically verify the implications of the model in the particularly interesting case of the Senegalese formal manufacturing sector. While the analysis of a single country does not allow to study the relationship between the development of formal institutions and the use of informal hiring channels, this paper could be the first step in further research on the cross-country analysis, since similar surveys exist for many countries. Our econometric results support the theoretical predictions that, conditional on being employed, when favoritism is widespread social networks are often exploited as hiring channel for unskilled jobs and when non-monetary gains are likely to be large (like in the case of relatives of the firm's head or in small firms). Formal hiring channels are instead adopted for filling skilled vacancies and when the required competences are higher. Finally, we find that workers hired through social networks suffer a wage penalty, which is increasing in absolute value with tie strength. ${ }^{45}$

From a policy perspective, it is important not only to investigate whether workers hired through social networks have wage penalties or premia imputable to their hiring channel, but also to understand the extent of the non-monetary benefits that they may enjoy. Moreover, wage differentials crucially depend on the bargaining power of workers and firms, so that the latter could represent a lever for policy intervention. Finally, an aspect that is not developed in the theoretical framework, but that plays a crucial role as far as policy is concerned, is that there may be situations where applicants don't have access to both hiring channels.

Further research could take into account some peculiar features implied by the use of the extended family as a hiring channel. For instance, family ties not only are very strong, but also provide almost full commitment among network members. If the chief of a firm guarantees employment to her relatives, the pooling of business risk ${ }^{46}$ within the family should be considered, too. 
Finally, a fundamental step would be taking into account the multi-dimensionality of concerns arising from incompleteness of information in the labor market and developing a theoretical framework that takes simultaneously into account moral hazard and selection problems. The predictions of a such model could then be empirically tested in order to disentangle the relative weight of the two. Indeed, a key difference between moral hazard and selection problems is that the latter fades away over time, while the former does not.

\section{Appendix A Theoretical appendix}

Proof of lemma 1. The worker chooses whether to $\operatorname{shirk}\left(\right.$ i.e., $\left.e^{k}=0\right)$ or not $\left(i . e ., e^{k}=e\right)$ by maximizing her utility.

If she was hired through formal channels, she does not shirk if $E_{n o-s h i r k i n g}^{F} \geq E_{\text {shirking' }}^{F}$, that is if:

$$
\frac{\left(w^{F}-\gamma e\right)(r+a)}{r(r+a+q)} \geq \frac{w^{F}(r+a)}{r\left(r+a+q+\mu^{F}\right)} .
$$

Therefore, the no-shirking condition for workers hired on the formal labor market is expression (5).

If she was hired through a social network, she does not shirk if $E_{n o-s h i r k i n g}^{N} \geq E_{\text {shirking, }}^{N}$, that is if:

$$
\frac{\left(w^{N}+\zeta-\gamma e\right)(r+a)}{r(r+a+q)} \geq \frac{\left(w^{N}+\zeta-\mu^{N} \varphi\right)(r+a)}{r\left(r+a+q+\mu^{N}\right)} .
$$

Thus, the no-shirking condition for workers hired through social networks is expression (6).

Proof of proposition 1. For hiring through social networks to arise, both the firm and the worker should prefer it:

1. the worker will accept a job from the informal channel if her life-time expected utility when hired through social networks is greater than or equal to what she could get if she was hired through the formal channel, that is, if $E^{N} \geq E^{F}$ :

$$
\frac{\left(w^{N}+\zeta-\gamma e\right)(r+a)}{r(r+a+q)} \geq \frac{\left(w^{F}-\gamma e\right)(r+a)}{r(r+a+q)}
$$

which implies expression (9); $\underline{w}^{N}$ is the lower bound of wages fulfilling this condition.

2. the firm prefers hiring through social networks, if per worker profits when hiring through informal channels (8) are greater than or equal to per worker profits when hiring through formal ones (7), that is, if $\Pi^{N} \geq \Pi^{F}$ :

$$
\frac{\vartheta e-w^{N}}{r+q}-\xi \frac{\gamma e(r+a+q)}{\left[w^{N}+\zeta-\gamma e+\varphi(r+a+q)\right](r+q)} \geq \frac{\vartheta e-w^{F}}{r+q}-\xi \frac{\gamma e(r+a+q)}{\left(w^{F}-\gamma e\right)(r+q)}
$$

which implies expression (10); $\bar{w}^{N}$ is the upper bound of wages fulfilling this condition.

Table 5 summarizes the variables introduced in the model. 


\begin{tabular}{llll}
\hline & Variable & Support & Index \\
\hline$k$ & Hiring channel & $k \in\{F, N\}$ & \\
$\eta_{i}$ & Worker's bargaining power & $0 \leq \eta_{i} \leq 1$ & $i=1, \ldots, n$ \\
$\gamma$ & Worker's cost of effort & $\gamma>0$ & \\
$e_{i}^{k}$ & Worker's effort & $e_{i}^{F} \in\{0, e\}$, & $k \in\{F, N\}$ and $i=1, \ldots, n$ \\
& & $e_{i}^{N} \in\{0, e\}$ & {$[$ basic framework] } \\
& & $e_{i}^{N} \in\left\{0, e+\delta \varphi_{i, j}\right\}$ & {$[$ [extended framework] } \\
$\vartheta$ & $\vartheta>0$ & \\
$\zeta_{i, j}$ & Productivity of effort & $\zeta_{i, j} \geq 0$ & $i=1, \ldots, n$ and $j=1, \ldots, m$ \\
$\varphi_{i, j}$ & Non-monetary benefit & $0<\varphi_{i, j} \leq 1$ & $i=1, \ldots, n$ and $j=1, \ldots, m$ \\
$\delta$ & Cultural factor & $\delta \in(-\infty,+\infty)$ & {$[$ extended framework] } \\
$\mu_{i, j}^{k}$ & Probability of monitoring & $0 \leq \mu_{i, j}^{k} \leq 1$ & $k \in\{F, N\}, i=1, \ldots, n$ and $j=1, \ldots, m$ \\
$\xi_{j}$ & Unit cost of monitoring & $\xi_{j}>0$ & $j=1, \ldots, m$ \\
$q$ & Probability of separation & $0 \leq 9 \leq 1$ & \\
$a$ & Job acquisition rate & $0 \leq a \leq 1$ & $k \in\{F, N\}, i=1, \ldots, n$ and $j=1, \ldots, m$ \\
$w_{i, j}^{k}$ & Worker's salary & $w_{i, j}^{k}>0$ &
\end{tabular}

\section{Appendix B Empirical appendix}

Endogenous switching models can be estimated one equation at a time either by twostep least square or maximum likelihood estimation. However, both of these estimation methods are inefficient. An efficient alternative is the full information maximum likelihood method (FIML) that simultaneously estimates binary and continuous parts of the model. ${ }^{47}$ Endogenous switching models describe the behavior of an agent with two regression equations, and a criterion function that determines which regime of wages the agent faces:

$$
\begin{aligned}
\ln w_{i}^{F} & =\beta^{F} X_{i}+\epsilon_{i}^{F} \\
\ln w_{i}^{N} & =\beta^{N} X_{i}+\epsilon_{i}^{N} \\
H_{i}^{*} & =\gamma Z_{i}+u_{i}
\end{aligned}
$$

where $w_{i}^{F}$ is the wage of individual $i$ who was hired through a formal channel, while $w_{i}^{N}$ is the wage of individual $i$ who was hired through some social network. $H_{i}^{*}$ is the latent variable that determines the hiring channel of individual $i . X_{i}$ is a vector of individual characteristics that is thought to influence the individual wage, while $Z_{i}$ is a vector of characteristics that influences the decision regarding the hiring channel. The parameter vectors are $\beta^{N}, \beta^{F}$, and $\gamma$. Finally, $\epsilon_{i}^{F}, \epsilon_{i}^{N}$, and $u_{i}$ are the disturbance terms. Notice that the impact of the hiring channel does not show up as a dummy variable in wage regressions, but rather in the fact that the constant term and the $\beta$-parameters may differ between the sample of workers hired through formal channels and the sample of workers hired through social networks (i.e., $\beta^{N} \neq \beta^{F}$ ). The difference in the constants yields the difference in average wages if a networked and a formally hired worker had $X_{i}=0$. The difference in the $\beta$-parameters represents how the returns to different observable wage determinants vary depending on the hiring channel. The observed dichotomous realization $\left(H_{i}\right)$ of the latent variable $H_{i}^{*}$ determining the hiring channel of individual $i$ has the following form:

$$
H_{i}= \begin{cases}1 & \text { if } H_{i}^{*}>0 \\ 0 & \text { otherwise }\end{cases}
$$


As in any model entailing latent variables, it is necessary to take care of identification. Endogenous switching models are identified by construction through non-linearities introduced by the selection equation (20). However, the goodness of estimations completely relies on the parametric assumptions about the distribution of error terms. Therefore, it is often preferred to add one or more exclusion restrictions. They are imposed by the researcher, based on economic intuition. By their very nature, exclusion restrictions are not testable, but indirectly. Therefore, $Z_{i}$ may include some or all variables in $X_{i}$, plus at least one additional variable that is legitimately excluded in wage regressions (18) and (19).

The main assumption of FIML is that $\epsilon_{i}^{F}, \epsilon_{i}^{N}$, and $u_{i}$ have a trivariate normal distribution, with mean vector zero and covariance matrix $\Omega$ as follows:

$$
\Omega=\left[\begin{array}{ccc}
\sigma_{u}^{2} & \cdot & \cdot \\
\sigma_{u F} & \sigma_{F}^{2} & \cdot \\
\sigma_{u N} & \cdot & \sigma_{N}^{2}
\end{array}\right]
$$

where $\sigma_{u}^{2}$ is the variance of the error term in the selection equation (20), and $\sigma_{F}^{2}$ and $\sigma_{N}^{2}$ are the variances of the error terms in the regression equations (18) and (19,) respectively. $\sigma_{u F}$ is the covariance of $u_{i}$ and $\epsilon_{i}^{F}$, and $\sigma_{u F}$ is the covariance of $u_{i}$ and $\epsilon_{i}^{N}$. The covariance between $\epsilon_{i}^{F}$ and $\epsilon_{i}^{N}$ is not defined, as $w_{i}^{F}$ and $w_{i}^{N}$ are never observed for the same worker.

To see whether sample selection is endogenous or exogenous, the correlation coefficients between residuals in each of the wage regressions and the hiring channel choice are estimated. The correlation between residuals in equation (18) and (20) is designated by $\rho_{F}$ :

$$
\rho_{F}=\frac{\sigma_{u F}}{\sigma_{u} \sigma_{F}}
$$

and the correlation between residuals in equation (19) and (20) by $\rho_{N}$ :

$$
\rho_{N}=\frac{\sigma_{u N}}{\sigma_{u} \sigma_{N}}
$$

If the unobserved factors determining the hiring choice are not correlated with unobserved determinants of wage, the selection is exogenous. In this case, the sorting into workers hired through formal and informal channel is random and there is no risk of a sample selection bias. The adoption of an endogenous switching model provides also crucial information concerning the indirect impact of the hiring channel on wages. Indeed, the switching model estimates a full set of interaction terms between the hiring channel of each worker and the impact of education, experience, and the other regressors in the wage equations. Therefore, for each wage determinant it is possible to assess whether its impact is dependent or independent of the channel whereby workers were hired. The combination of the switching impact of observable determinants of wage and the unobserved factors allows to draw a conclusion concerning the existence of a wage penalty or premium to workers hired through social networks.

Table 6 shows a summary of variables. 
Table 6 Description of variables used in the empirical analysis (Sections 2 and 4)

\begin{tabular}{|c|c|}
\hline Variables & Description \\
\hline \multicolumn{2}{|l|}{ Firms: } \\
\hline Sector & $\begin{array}{l}\text { Categorical variable indicating the manufacturing sector to which a } \\
\text { firm belongs }\end{array}$ \\
\hline Location & Dummy variable indicating whether a firm is located in Dakar or elsewhere \\
\hline Public firms & $\begin{array}{l}\text { Dummy variable categorizing a firm as public if more than } 45 \% \text { of its } \\
\text { capital belongs to State }\end{array}$ \\
\hline Owner and director & $\begin{array}{l}\text { Dummy variable indicating whether the owner of a firm is also its director } \\
\text { or manager }\end{array}$ \\
\hline Mainly informal hiring channels & Number of firms that declared to mainly hire through informal channels \\
\hline Number of employees & Number of employees working in a firm \\
\hline \multicolumn{2}{|l|}{ Workers: } \\
\hline Education & Number of years of education \\
\hline Previous experience & Number of year of experience before being hired in current firm \\
\hline Age & Worker's age at hiring time \\
\hline Gender & Dummy variable indicating worker's gender \\
\hline Origin & Categorical variable indicating worker's place of origin \\
\hline Marital status & Dummy variable indicating whether a worker is married \\
\hline Same ethnicity as firm's head & $\begin{array}{l}\text { Dummy variable indicating whether a worker belongs to the same ethnic } \\
\text { group as the owner or the manager running the firm }\end{array}$ \\
\hline Same family as firm's head & $\begin{array}{l}\text { Dummy variable indicating whether a worker belongs to the extended family } \\
\text { of the owner or the manager running the firm }\end{array}$ \\
\hline Job & Categorical variable indicating the type of job for which a worker was hired \\
\hline Hours worked & Number of hours worked per week \\
\hline Ln real monthly salary & $\begin{array}{l}\text { Natural logarithm of worker's monthly salary when she was hired, adjusted } \\
\text { for HCPI }\end{array}$ \\
\hline Hiring channel & Dummy variable stating whether a worker was hired through social network \\
\hline
\end{tabular}

\section{Endnotes}

${ }^{1}$ We follow the literature in using the expression 'informal hiring channel' to indicate that a social network served as information channel for a hiring.

${ }^{2}$ See Fernandez et al. (2000) for an interesting review of economic and sociological competing theories providing a rational for the use of informal hiring channels.

${ }^{3}$ See Ben-Porath (1980) and Fafchamps (2006), who suggests that reliance on interpersonal relationships and networks can be seen as a symptom that formal institutions do not work well.

${ }^{4}$ See Rees (1966), Rees and Schultz (1970), Corcoran (1980), Banerjee (1984), Pistaferri (1999), Antoninis (2006), Munshi and Rosenzweig (2006), and Pellizzari (2009).

${ }^{5}$ Kugler (2003), for example, argues that the use of referrals is more widespread in highskilled occupations.

${ }^{6}$ While Simon and Warner (1992) and Kugler (2003) conclude that workers hired through social networks get wage premia with respect to employees hired through formal channels, penalties are found by Pistaferri (1999) and Bentolila et al (2010).

${ }^{7} \mathrm{~A}$ tight network is characterized by strong ties. Different concepts of strong ties populate the literature. Hennig and Lieberg (1996) and Wahba and Zenou (2005) define strong ties as those based on a repeated and regular relationship, while Grieco (1987), Lin (1999) and others measure the strength of the ties by the degree of commitment, reciprocity, trust and mutual obligation. Our preferred notion is the one proposed by Granovetter (1973): "The strength of a tie is a (probably linear) combination of the amount of time, the 
emotional intensity, the intimacy (mutual confiding), and the reciprocal services which characterize the tie".

${ }^{8}$ One recent exception is Zenou (2011), where geographical distance plays the role of tightness.

${ }^{9}$ Several studies support this insight. Adler and Kwon (2002) suggest that tight networks encourage compliance with rules and reduce the need for formal controls. Similarly, Grieco (1987) argues that social networks can reinforce social control at the work place. Kirabo and Schneider (2011) emphasize that social networks reduce moral hazard through social punishment or social collateral even in developed countries. Moreover, Fisman (2003) provides evidence that enforcement is particularly effective within ethnic groups in Africa. Finally, Binzel and Fehr (2010), Glaeser et al. (1990), Barr (2004) and Miller and Rosenbaum (1997) provide experimental evidence of the positive relationship between social proximity and trustworthiness.

${ }^{10}$ In the Ivorian manufacturing sector the trade-off between wage and monitoring has been analyzed by Azam and Lesueur (1997).

${ }^{11}$ In enriching the employer search framework with the efficiency wage theory, we carry out a step along the research path wished by Sicilian (1995). In a similar spirit Kugler (2003) also argues that referees can exert peer pressure on co-workers and thus lower monitoring cost within a matching framework.

${ }^{12}$ In a sense, the 'cultural parameter' in the theoretical framework presented in Section 3 captures what Loury (2006) interprets as due to two different types of links.

${ }^{13}$ An example of the economic relevance of informality in Africa is provided by Azam et al (2001) concerning the credit market.

${ }^{14}$ Luke and Munshi (2006) and Magruder (2010) find that traditional social networks, such as those based on kinship, are pivotal for labor markets respectively in Kenya and South Africa. Barr and Oduro (2002) stress the importance of ethnic networks for labor outcomes in Ghana.

${ }^{15}$ This empirical approach to our knowledge has only been applied to investigating informal hiring channels by Delattre and Sabatier (2007). They find that in France previously unemployed people suffer a wage penalty imputable to the use of strong ties as hiring channel.

${ }^{16}$ The survey defines the formal sector as made up by registered firms. However, there are many other firms that do not officially exist (and thus do not pay taxes). The latter firms make up the so-called informal sector of the economy, which represents a notable part of the economy and employs a great number of workers. Data available for 2001 indicate that it represented almost 55\% of GDP and that about 1.2 million people worked in informal firms. However, the informal sector of the economy is likely to hire almost exclusively through social networks. Thus, the formal sector is a more interesting ground to pin down the determinants of firms' choices concerning the hiring channel.

${ }^{17}$ The fact that sampled firms belong to the manufacturing sector implies that it is not possible to reach conclusions about the overall Senegalese economy. However, the manufacturing sector is a large part of it, accounting for 12\% of GDP in 2008 (African Economic Outlook 2009). The survey is designed to be representative and to adequately cover SMEs.

${ }^{18}$ Notice that the focus of this paper is on the hiring channel and not on the characteristics of the contract hold by workers. Indeed, the ICA survey does not provide information 
on workers' contract, i.e., whether it is written and complete, whether it specifies benefits and social insurance, etc. However, Combarnous (2001) shows that in Côte d'Ivoire workers who found their job through informal channels usually have incomplete contracts, while employees holding complete contracts often applied to a vacancy announcement.

${ }^{19}$ Indeed, more than 2 million people live in Dakar, while less than 250 thousands in the other cities. Thus, the concentration in Dakar of interviewed workers is almost representative.

${ }^{20}$ Notice that the information available concerns neither the pool of applicants, nor justhired workers, but workers employed at the time the survey took place.

${ }^{21} 99 \%$ of sampled workers answered the question about whether they belong to the same ethnic group as that of the firm manager or owner. Notice that the survey does not report the ethnic group of interviewed workers. Senegal has a wide variety of ethnic groups. The main ethnic groups are the Wolof (41\%), the Fula and Toucouleur (26\%), and the Serer (15\%).

${ }^{22}$ As in the case of ethnic group, 99\% of workers answered to the question 'Are you a relative of the firm manager or owner?'. Unfortunately, the precise type of link is not specified in the survey.

${ }^{23}$ Unfortunately, the data on each individual's social links are not available. Therefore, we proxy network tightness based on the available information, like Patacchini and Zenou (2012).

${ }^{24}$ The survey categorizes workers into ten types of jobs. We group them into four occupational categories: manager, skilled white collar (engineer, scientist, economist, programmer, mathematician, accountant), skilled blue collar and other skilled (technician, supervisor, maintenance and repairing man, medical staff, clerk, secretary), and unskilled (other production worker, guard, cook).

${ }^{25}$ Real wages are computed adjusting reported salaries at the time of hiring for the harmonized consumer price index, provided by the Senegalese Forecasting and Statistics Direction (Direction de la Prévision et de la Statistique). Notice that the questionnaire asks workers to report their salary at the time of hiring, which may imply a recall bias.

${ }^{26}$ Table 5 in Appendix A summarizes the variables introduced in the model.

${ }^{27}$ In the mathematical expressions that follow $i$ and $j$ are omitted for the sake of readability.

${ }^{28}$ Efficiency wage theories are based on the idea that low wages may have a negative incentive effect. Employers may then be reluctant to cut wages, even in the presence of an excess supply of labor, because reducing wages may affect productivity more than proportionately and increase the cost of labor. Efficiency wage models may provide a microfoundation for Keynesian wage rigidity, an explanation for unemployment and for wage differentials across firms and industries. Katz (1986) provides a review and an evaluation of the efficiency wage literature. As far as African countries are concerned, Ezeala Harrison (1992) and Fafchamps and Söderbom (2006) find empirical evidence in support of efficiency wage theory.

${ }^{29}$ The potential role played by non-pecuniary benefits is stressed by Fontaine (2008) and Bentolila et al. (2010) It is likely that such gains depend somehow on network tightness. However, the model is agnostic concerning the specific functional form describing this potential relationship, since the latter is far from being obvious. While this simplification entails that tightness explicitly appears only with a negative sign into the worker's 
utility function, the key point is of course accounting for the net impact of tightness on it.

${ }^{30}$ Interestingly enough, Pellizzari (2009) finds wage penalties in Italy and wage premia in countries like Belgium and the Netherlands.

${ }^{31}$ It would be very interesting to test our theoretical insights concerning the role played by informal hiring channels in different institutional contexts, but a systematic cross-country comparison is beyond the purposes of this paper.

${ }^{32}$ Sample selection is an issue because we observe wages of workers hired through a social network only when they were hired through that channel (and never if they were hired through formal channels).

${ }^{33}$ Since our focus is on the choice of the hiring channel, variables should refer to the hiring time of each worker. Even though some variables explicitly refer to that time (hiring channel, type of job, salary and previous experience), the large majority of them concerns the year of the survey. However, some information obtained in 2003 may well approximate several variables at the hiring time. For instance, the years of education declared at the time of the survey are likely to correspond to the years of education at hiring time. Therefore, we assume that some variables at the firm (size, sector, location, public capital, and whether the director is also the owner) and the worker (years of education, hours of work and marital status) level are good proxies for their value at the time hiring occurred. ${ }^{34}$ We run the same estimation using the hours of work per week to obtain the wage rates from the monthly salaries. The results are very similar. However, we present the results obtained for monthly wages in order to avoid any concern of propagation of potential measurement errors from hours of work to the dependent variable.

${ }^{35}$ Other potential exclusion restrictions that we tested were the distance to work, in terms of both minutes and kilometers. However, both measures of distance are weak determinants of the hiring channel.

${ }^{36}$ Hayashi (2000) precisely cites age as example of a good instrument for wage regressions that include education and experience in the section dedicated to endogeneity bias of his textbook on Econometrics (pages 199-200).

${ }^{37}$ While 40 years old is an arbitrary threshold to proxy old age, adopting age at hiring as instrument yields virtually the same results (available upon request). Moreover, although 40 years old is quite young, in an African context that represents a reasonable threshold proxying an elder age as far as the labor market is concerned (life expectancy is about 60 years old in Senegal and the World Health Organization states that the definition of an elderly person in Africa should be around 50 years of age, from a health point of view).

${ }^{38}$ Significant wage penalties suffered by workers hired through their relatives are also found by Nordström Skans and Kramarz (2011).

${ }^{39}$ Since we do not separately observe the hiring choices of firms and applicants, but only the outcome of their joint decisions (i.e., that someone is working for a firm), some caution is needed in interpreting these results. However, the magnitude of coefficients undoubtedly points to their consistency with a context of favoritism.

${ }^{40}$ The same result is found for example by Pistaferri (1999).

${ }^{41} \mathrm{An}$ intriguing interpretation is that networks that have served as hiring channel constitute a guarantee of trustworthiness, substituting marital status in the formal labor market. ${ }^{42}$ This finding is coherent with the view that big cities entail weaker social networks, an idea that dates back to the nineteenth century (see Tönnies 1887 and Simmel 1903) and 
was developed by the social disorganization theory (see Wirth 1938, Redfield 1947 and Alexander 1966) and the overload theory (see Milgram 1970). For a short and enlightening discussion on the topic in sociology, see Amato (1993).

${ }^{43}$ While the qualitative result is intuitive, the magnitude of the coefficients needs to be taken cum grano salis, since $96 \%$ of sampled employees work in Dakar.

${ }^{44}$ Pistaferri (1999) also finds that large firm are less likely to hire through informal channels and pay higher wages. More in general, the fact that larger firms tend to pay higher wages is a well-established finding (see for instance Oi and Idson 1999).

${ }^{45}$ The finding that workers hired through social networks suffer a wage penalty with respect to other workers in the Senegalese manufacturing sector might be, at least partly, compensated by non-monetary gains, which are not captured by the empirical analysis.

${ }^{46}$ Several empirical studies find evidence of risk pooling within highly clustered networks in African countries (see for example Barr and Genicot (2008)).

${ }^{47}$ FIML involves forming the joint distribution of the random variables characterizing the equations of the model and then maximizing the full log-likelihood function. In this paper the estimation of the switching regression model and the counterfactuals are based on the FIML algorithm implemented as a Stata program (movestay) by Lokshin and Sajaia (2004).

\section{Competing interests}

The IZA Journal of Labor \& Development is committed to the IZA Guiding Principles of Research Integrity. The author declares that she has observed these principles.

\section{Acknowledgements}

We thank for constructive and insightful comments anonymous referees, participants at IARIW, AFSE, DIME, ADRES, and EEA conferences, Bicocca and OECD Development Centre seminar, IZA and GREQAM summer schools, and J.P.Azam, S.Avouyi-Dovi, R.Berlinschi, P.Dubois, G.Fields, G.Friebel, J.Y.Lesueur, M.O.Jackson, E.La Ferrara, M.Gilli, J.Miquel-Florensa, J.Ortega, L.Pagani, F.Portier, R.Rathelot, F.Salanié, P.Seabright, N.Treich, G.Verdugo, and Y.Zenou. The views expressed in this paper are those of the authors and do not necessarily represent those of their institutions.

Responsible editor: Jackline Wahba

Received: 2 October 2012 Accepted: 24 February 2013

Published: 29 April 2013

\section{References}

Adler PS, Kwon S (2002) Social capital: Prospects for a new concept. Acad Manage Rev 27: 17-40 African Economic Outlook (2009) OECD and African Development Bank. OECD Publishing, Paris

Alexander C (1966) The city as a mechanism for sustaining human contact. Center for Planning and Development Research, University of California

Amato PR (1993) Urban-rural differences in helping friends and family members. Soc Psychol Q 56(4): 249-262

Antoninis M (2006) The wage effects from the use of personal contacts as hiring channels. J Econ Behav Organ 59: 133-146

Assaad R (1997) Kinship ties, social networks and segmented labor markets: evidence from the construction. J Dev Econ 52: $1-30$

Azam JP, Biais B, Dia M, Maurel C (2001) Informal and formal credit markets and credit rationing in Côte d'Ivoire. Oxf Rev Econ Policy 17(4): 520-534

Azam JP, Lesueur JY (1997) Efficiency-wage and supervision: Theory and application to the Ivoirian manufacturing sector. J Afr Econ 6(3): 445-462

Banerjee B (1984) Information flow, expectations and job search. J Dev Econ 15: 239-257

Barr A (2004) Kinship, familiarity, and trust: An experimental investigation. Foundations of Human Sociality: Economic experiments and ethnographic evidence from fifteen small-scale societies. Oxford University Press on Demand, Oxford

Barr A, Genicot G (2008) Risk-pooling, commitment, and information: An experimental test. Eur J Econ Assoc 6(6): $1151-185$

Barr A, Oduro A (2002) Ethnic fractionalization in an African labour market. J Dev Econ 68(2): 355-379

Ben-Porath Y (1980) The f-connection: Families, friends, and firms and the organization of exchange. Popul Dev Rev 6: 1-30

Bentolila S, Michelacci C, Suarez J (2010) Social contacts and occupational choice. Economica 77(305): 20-45

Binzel C, Fehr D (2010) Social relationships and trust. DIW Berlin Discussion Paper. 1007

Combarnous F, Labazée P (2001) Typologie des contrats, mode de rémunération des travailleurs et segmentation dans les entreprises modernes de Côte d'Ivoire. Entreprises et emploi en Côte d'Ivoire, Volume Serie de Recherche 5. Entreprises et emploi en Côte d'Ivoire. Université Montesquieu-Bordeaux IV, Pessac, France

Corcoran M (1980) Most workers find jobs through word of mouth. Mon Labor Rev 103(8): 33-35

Delattre E, Sabatier M (2007) Social capital and wages: An econometric evaluation of social networking's effects. Labour 21(2): 209-236 
Ezeala-Harrison F (1992) An empirical framework for the efficiency-wage model: Use of micro data for Nigeria. J Econ Stud 19(3): 18-35

Fafchamps M (2006) Development and social capital. J Dev Stud 42(7): 1180-11-98. Taylor \& Francis

Fafchamps, M (2009) Referral and job performance: Evidence from the Ghana colonial army. CSAE Working Paper Series. Centre for Economic Policy Research

Fafchamps M, Söderbom M (2006) Wages and labor management in African manufacturing. J Hum Resour 41 (2): 356-379

Fernandez RM, Castilla EJ, Moore P (2000) Social capital at work: Networks and employment at a phone center. AJS 105: $1288-356$

Fisman RJ (2003) Ethnic ties and the provision of credit: Relationship-level evidence from African firms. Advances Econ Anal \& Policy 3(1): art.4

Fontaine F (2008) Why are similar workers paid differently? the role of social networks. J Econ Dyn Control 32(12): 3960-3977

Glaeser EL, Laibson DI, Scheinkman JA, Soutter CL (1990) Measuring trust. Q J Econ 115(3): 811-846

Granovetter M (1973) The strength of weak ties. AJS 78: 1360-1380

Grieco M (1987) Keeping it in the family: social networks and employment chance. Routledge Kegan \& Paul, Tavistock, London

Hayashi F (2000) Econometrics. Princeton University Press, Princeton, NJ

Heckman JJ (1979) Sample selection bias as a specification error. Econometrica 47(1): 153-161

Hennig C, Lieberg M (1996) Strong or weak ties? Neighbourhood networks in a new perspective. Scand Housing Plann Res 13: 3-26

Holzer HJ (1988) Search method use by unemployed youth. J Labor Econ 6: 1-20

loannides YM, Loury L (2004) Job information networks, neighborhood effects, and inequality. J Econ Lit 42: 1056-1093

Katz LF (1986) Efficiency wage theories: A partial evaluation. NBER working papers. In: NBER Macroeconomics Annual 1986, vol 1, 235-290. MIT Press

Kirabo J, Schneider H (2011) Do social connections reduce moral hazard? evidence from the New York City taxi industry Am Econ J: Appl Econ 3: 244Ű267

Kugler AD (2003) Employee referrals and efficiency wages. Labor Econ 10: 531-556

Lin N (1999) Social networks and status attainment. Ann Rev Sociol 25(1): 467-487

Lokshin M, Sajaia Z (2004) Maximum-likelihood estimation of endogenous switching regression models. STATA Journal 4(3): 227-34

Loury L (2006) Some contacts are more equal than others: Informal networks, job tenure, and wages. J Labor Econ 24(2): 299-318

Luke N, Munshi K (2006) New roles for marriage in urban Africa: Kinship networks and the labor market in Kenya. Rev Econ Stat 88(2): 264-282

Magruder J (2010) Intergenerational networks, unemployment, and persistent inequality in South Africa. Am Econ J: Appl Econ 2(1): 62-85

Milgram S (1970) The experience of living in cities. Science 167(3924): 1461-1468

Miller S, Rosenbaum J (1997) Hiring in a hobbesian world. social infrastructure and employers' use of information. Work and Occupations 24(4): 498-523

Montgomery J (1991) Social networks and labour market outcomes: Toward an economic analysis. Am Econ Rev 81(5): 1408-1418

Munshi K, Rosenzweig M (2006) Traditional institutions meet the modern world: Caste, gender, and schooling choice in a globalizing economy. Am Econ Rev 96(4): 1225-1252

Nordström Skans O, Kramarz F (2011) When strong ties are strong: networks and youth labor market entry. IFAU -Institute for Evaluation of Labour Market and Education Policy

Oi WY, Idson TL (1999) Firm size and wages(Ashenfelter O, Card D, eds.). Elsevier, Amsterdam

Patacchini E, Zenou Y (2012) Ethnic networks and employment outcomes. Reg Sci Urban Econ 42(6): 938-949

Pellizzari M (2009) Do friends and relative really help in getting a good job? Ind Labor Relat Rev 63(3): 494-510

Pistaferri L (1999) Informal networks in the Italian labor market. Giornale degli Economisti e Annali di Economia 58: 355-375

Redfield R (1947) The folk society. AJS 53: 293-308

Rees A (1966) Information networks in labor markets. Am Econ Rev 56: 559-566

Rees A, Schultz G (1970) Workers in an Urban Labor Market. University Of Chicago Press, Chicago, II, USA

Rubinstein A (1982) Perfect equilibrium in a bargaining model. Econometrica 50(1): 97-109

Saloner G (1985) Old boy networks as screening mechanism. J Labor Econ 3: 255-267

Shapiro C, Stiglitz JE (1984) Equilibrium unemployment as a worker discipline device. Am Econ Rev 74(3): 433-444

Sicilian P (1995) Employer search and worker-firm match quality. Q Rev Econ Finance 35: 515-532. Elsevier

Simmel G (1903) Die Grosstädte und das Geistesleben. Petermann, Dresden, Petermann

Simon JC, Warner T (1992) Matchmacker, matchmaker: the effect of the old boy networks on job match quality, earnings and tenure. J Labor Econ 10(3): 306-330

Tönnies F (1887) Gemeinschaft und Gesellsschaft. Fues's Verlag, Leipzig

Wahba J, Zenou Y (2005) Density, social networks and job search methods: Theory and application to Egypt. J Dev Econ 78: 443-473

Wirth L (1938) Urbanism as a way of life. AJS 33: 57-71

Zenou Y (2011) Spatial versus social mismatch: The strength of weak ties. J Urban Econ 74(C): 113-132. IZA Discussion Paper 5507. Elsevier

doi:10.1186/2193-9020-2-3

Cite this article as: Berardi: Social networks and wages in Senegal's labor market. IZA Journal of Labor \& Development $20132: 3$ 